\title{
Identification and Assessment of Adherence-Enhancing Interventions in Studies Assessing Medication Adherence Through Electronically Compiled Drug Dosing Histories: A Systematic Literature Review and Meta-Analysis
}

\author{
Jenny Demonceau - Todd Ruppar - Paulus Kristanto - Dyfrig A. Hughes • \\ Emily Fargher · Przemyslaw Kardas $\cdot$ Sabina De Geest $\cdot$ Fabienne Dobbels $\cdot$ \\ Pawel Lewek · John Urquhart · Bernard Vrijens $\cdot$ for the ABC project team
}

Published online: 16 April 2013

(C) The Author(s) 2013. This article is published with open access at Springerlink.com

\begin{abstract}
Background Non-adherence to medications is prevalent across all medical conditions that include ambulatory pharmacotherapy and is thus a major barrier to achieving the benefits of otherwise effective medicines.

Objective The objective of this systematic review was to identify and to compare the efficacy of strategies and components thereof that improve implementation of the prescribed drug dosing regimen and maintain long-term persistence, based on quantitative evaluation of effect sizes across the aggregated trials.

Data sources MEDLINE, EMBASE, CINAHL, the Cochrane Library, and PsycINFO were systematically searched for randomized controlled trials that tested the efficacy of adherence-enhancing strategies with selfadministered medications. The searches were limited to
\end{abstract}

Electronic supplementary material The online version of this article (doi:10.1007/s40265-013-0041-3) contains supplementary material, which is available to authorized users.

J. Demonceau · P. Kristanto · J. Urquhart · B. Vrijens AARDEX Group Ltd., a MWV Healthcare Company, Sion, Switzerland

T. Ruppar · S. De Geest · F. Dobbels

Health Services and Nursing Research, Department of Public

Health, University of Leuven, Leuven, Belgium

\section{T. Ruppar}

Sinclair School of Nursing, University of Missouri,

Columbia, USA

D. A. Hughes · E. Fargher

Centre for Health Economics and Medicines Evaluation,

Bangor University, Bangor, Wales

P. Kardas · P. Lewek

Medical University of Lodz, Lodz, Poland papers in the English language and were included from database inception to 31 December 2011.

Study selection Our review included randomized controlled trials in which adherence was assessed by electronically compiled drug dosing histories. Five thousand four hundred studies were screened. Eligibility assessment was performed independently by two reviewers. A structured data collection sheet was developed to extract data from each study.

Study appraisal and synthesis methods The adherenceenhancing components were classified in eight categories. Quality of the papers was assessed using the criteria of the Cochrane Handbook for Systematic Reviews of Interventions guidelines to assess potential bias. A combined adherence outcome was derived from the different adherence variables available in the studies by extracting from each paper the available adherence summary variables in a pre-defined order (correct dosing, taking adherence, timing adherence, percentage of adherent patients). To study the

\section{S. De Geest}

Institute of Nursing Science, Faculty of Medicine, University of Basel, Basel, Switzerland

\section{J. Urquhart}

Department of Bioengineering and Therapeutic Sciences, UCSF, San Francisco, USA

\section{B. Vrijens}

Department of Biostatistics and Medical Informatics,

University of Liège, Liège, Belgium

B. Vrijens $(\square)$

AARDEX Group Ltd, Rue des Cyclistes Frontière,

24, 4600 Visé, Belgium

e-mail: bernard.vrijens@aardexgroup.com 
association between the adherence-enhancing components and their effect on adherence, a linear meta-regression model, based on mean adherence point estimates, and a meta-analysis were conducted.

Results Seventy-nine clinical trials published between 1995 and December 2011 were included in the review. Patients randomized to an intervention group had an average combined adherence outcome of $74.3 \%$, which was $14.1 \%$ higher than in patients randomized to the control group $(60.2 \%)$. The linear meta-regression analysis with stepwise variable selection estimated an $8.8 \%$ increase in adherence when the intervention included feedback to the patients of their recent dosing history (EMfeedback $)(p<0.01)$ and a $5.0 \%$ increase in adherence when the intervention included a cognitive-educational component $(p=0.02)$. In addition, the effect of interventions on adherence decreased by $1.1 \%$ each month. Sensitivity analysis by selecting only high-quality papers confirmed the robustness of the model. The random effects model in the meta-analysis, conducted on 48 studies, confirmed the above findings and showed that the improvement in adherence was $19.8 \%(95 \%$ CI 10.7-28.9\%) among patients receiving EM-feedback, almost double the improvement in adherence for studies that did not include this type of feedback [10.3\% (95\% CI $7.5-13.1 \%)](p<0.01)$. The improvement in adherence was $16.1 \%$ (95\% CI 10.7-21.6\%) in studies that tested cognitive-educational components versus $10.1 \%(95 \% \mathrm{CI}$ 6.6-13.6\%) in studies that did not include this type of intervention $(p=0.04)$. Among 57 studies measuring clinical outcomes, only 8 reported a significant improvement in clinical outcome.

Limitations Despite a common measurement, the metaanalysis was limited by the heterogeneity of the pooled data and the different measures of medication adherence. The funnel plot showed a possible publication bias in studies with high variability of the intervention effect.

Conclusions Notwithstanding the statistical heterogeneity among the studies identified, and potential publication bias, the evidence from our meta-analysis suggests that EMfeedback and cognitive-educational interventions are potentially effective approaches to enhance patient adherence to medications. The limitations of this research highlight the urgent need to define guidelines and study characteristics for research protocols that can guide researchers in designing studies to assess the effects of adherence-enhancing interventions.

\section{Introduction}

Adequate adherence to medications of proven efficacy and acceptable safety is essential for realizing their health benefits. Yet, suboptimal adherence to prescribed medication regimens is prevalent across all clinical conditions and populations [1].

In the setting of chronic conditions, non-adherence to medications generally worsens outcomes of treatments, leading to increased risk of adverse medical events, more consultations with physicians, higher rates of hospitalization, and increased health care costs [1-5]. Non-adherence has recently been estimated to cost the US health care system $\$ 310$ billion annually [6] with the associated economic burden being specific to disease severity, co-morbidity, and the respective severities of co-morbidities [7].

Many reasons exist for non-adherence to medicines, and knowledge of these could help clinicians to target patients in need of intervention, design these interventions, and help researchers to plan studies of adherence.

Several reviews [8-11] of interventions for enhancing adherence to medications have consistently highlighted methodological weaknesses in the study designs and methods used, often precluding quantification and permitting only qualitative assessments. In particular, there are major between-study differences in methods used to assess adherence, differing not only in reliability but also in the degree of temporal resolution of their measurements. These methodological differences have thus hampered the identification of interventions that can effectively enhance adherence to medications.

Among the different measurement methods available, electronic medication-event monitoring, which consists of automatic compilation of the time history of each patient's entry into the drug package, has been considered to provide the most reliable data on adherence in complex clinical situations and in the setting of clinical trials and adherence research [1]. Moreover, it has been reported that electronic medication-event monitoring is the most accurate method for identifying non-adherence [12-14]. Several studies confirm that package opening times are a robust indicator of the times at which patients take the prescribed doses [15-17].

Electronically-compiled dosing histories may also be used as part of the adherence-enhancing intervention, by allowing the health professional to provide feedback to the patient on his/her dosing history. This approach has been referred to as "Measurement-Guided Medication Management (MGMM)" [4].

In the present study, we have systematically searched the literature to identify randomized controlled trials (RCTs) containing empirical data on the efficacy of interventions to enhance adherence to prescribed medications, as assessed by electronic medication-event monitoring methods.

This research was performed within the Ascertaining Barriers to Compliance (ABC) Project, which is an 
international collaboration of European research groups in the field of adherence to medications funded by the European Commission, Seventh Framework Programme [18].

\section{Methods}

The reporting of this systematic review follows the PRISMA guidelines [19].

\subsection{Eligibility Criteria}

We included RCTs, including cross-over and cluster-randomized trials, containing empirical data on interventions expected to enhance adherence to prescribed medications in adults and children, where adherence was assessed by electronic medication-event monitoring methods.

Papers were excluded for the following reasons:

(1) Studies that did not focus on adherence to medications; (2) studies in which adherence was not measured electronically in all patients enrolled in the clinical trial; (3) studies that were not RCTs; (4) studies that focused on interventions to improve disease or symptom management; (5) studies that did not include an adherence intervention; (6) studies in which no quantifiable adherence data were reported; (7) studies that did not report a formal comparison of adherence data between intervention and control conditions; (7) double citations. No paper was excluded on the grounds of quality.

\subsection{Information Sources}

MEDLINE, EMBASE, CINAHL, the Cochrane Library, and PsycINFO were searched for all papers testing adherence-enhancing interventions. The searches were limited to papers in the English language and were included from database inception to 31 December 2011. Detailed search strategies specific to the different databases are provided in Appendix 1 in the Electronic Supplementary Material (ESM).

\subsection{Study Selection}

Eligibility assessment of title and abstract was performed independently in an unblinded standardized manner by two reviewers (JD, TR). If one reviewer coded a study as potentially eligible, the paper was included for full-text review. The full texts of potentially eligible papers were retrieved and reviewed in the second stage of the screening process. Disagreements were resolved by discussion, and a final decision was reached between the two reviewers.

\subsection{Data Collection Process}

A structured data collection sheet was developed to extract data from each study. All data were extracted from the papers; no additional information was sought from authors. The following paragraphs describe which data were extracted.

\subsection{Data Items}

\subsubsection{Types of Participants}

Studies including ambulatory patients who were prescribed medications for any medical disease were considered for this review.

Demographic data, such as sample size of each study group, population age, percentage of female subjects in each group, and ethnicity of the patients, were extracted from each paper.

\subsubsection{Categorization of Interventions}

Any intervention or combination of interventions intended to affect adherence to self-administered prescribed medications in short-term and in long-term therapy.

The adherence-enhancing components were classified in eight categories, based on a taxonomy developed from other sources [10, 20-22].

1. Interventions based on a treatment simplification (TRT simpl) consist of changes in the dosage schedule (e.g., once daily vs. twice daily) or a change in formulation (e.g., change from tablets to liquid formulation);

2. Cognitive-educational interventions (Cogn-Educ) present information individually or in a group setting, delivering it verbally, in written form, and/or audiovisually. These interventions are designed to educate and motivate patients based on the concept that patients who understand their condition and its treatment will be more informed, more empowered and more likely to adhere [10, 20, 21];

3. Behavioral-counseling interventions (Behav-Counsel) shape and/or reinforce behavior, and empower patients to participate in their own care, while positively changing their skill levels or normal routines (e.g., skill building by a health care professional, pillboxes, calendars, steps intended to remind the patient to take the medication or tailor the regimen to the patient's daily routine) and problem solving [10, 20, 21];

4. Social-psycho-affective interventions (Soc-Psych) focus on patients' feelings and emotions or social relationships and social support (e.g., family counseling, group meetings with peers or another groups, 
stress management) [10, 20], as long as the interventions are based on the assumptions that cognitions can be monitored and altered, and in turn may facilitate behavior change [22];

5. Interventions based on electronically monitored adherence feedback (EM-feedback) are designed to provide feedback on patients' dosing histories compiled from electronic medication-event methods;

6. Interventions based on technical reminder systems (Tech rem) are designed to provide technical devices to remind the patients when it is time to take their medications (e.g., mobile phone text message, pager, electronic monitor with beeper);

7. Interventions using technical equipment for monitoring the disease being managed (Tech equip) are designed to use various technologies to provide patients with feedback on a clinical outcome (e.g., glucose meter, BP home measurement, feedback on laboratory results);

8. Rewards: any kind of rewards for adhering to medication (e.g., cash reinforcement, toys for children).

\subsubsection{Types of Studies}

Randomized controlled trials, including cross-over and cluster-randomized trials, which tested the effectiveness of adherence-enhancing interventions in an intervention group versus a control group receiving no intervention, e.g., usual care. Adherence had to be assessed through electronically compiled dosing histories in all patients. Studies with small sample sizes were included. Although they often lack statistical power, small studies sometimes contribute novel interventions or target difficult-to-recruit populations.

cStudy design, number of monitored medications, types of electronic medication-event monitoring, and information on the condition being managed (medical condition, regimen, type of administration) were extracted from each study.

\subsubsection{Types of Outcome Measures}

Studies in which medication adherence was reported as the primary or secondary outcome assessed with any kind of electronic medication-event monitoring system. We did not assess the quality of the selected studies in regard to whether or not the study was appropriately powered to detect differences in adherence. Clinical outcomes were extracted if reported.

2.5.4.1 Adherence Definitions A range of variables was extracted, according to reporting in the primary studies.
These were labeled as follows over the relevant reporting period:

- Correct dosing was defined as the percentage of treatment days with the correct number of doses taken;

- Taking adherence was defined as the percentage of prescribed doses taken;

- Timing adherence was defined as the percentage of doses taken within a pre-defined time window;

- Percentage of adherent patients was defined as the percentage of patients with adherence measures greater than a pre-defined value.

Data on mean adherence outcomes were extracted for each reported adherence variable, with a $95 \%$ confidence interval (CI) or standard deviation (SD) for all the study groups. Each study may however report the result of the adherence intervention using one summary variable and not the others. Therefore, to take into account all studies available for the analysis, a combined adherence outcome was defined by selecting the available adherence summary variable of each paper in the following order: correct dosing, taking adherence, timing adherence, and percentage of adherent patients. To study the association between the adherence-enhancing components and their effect on adherence, the analyzed outcome variable was the difference in reported adherence percentages between the intervention group and the control group. If adherence outcomes were reported at several time points, the outcome reported at the end of the intervention period was coded for each study.

2.5.4.2 Health Outcomes Data on clinical outcomes were extracted and reported as a significant or non-significant difference between study groups. We did not assess the quality of the selected studies with regard to whether or not the study was appropriately powered to detect differences in clinical outcomes.

\subsection{Risk of Bias in Individual Studies}

A quality assessment of the articles included in this review was processed by two independent reviewers (PK, JD) after the data collection process. The evaluation was based on the assessment of potential bias as reported in the Cochrane Handbook for Systematic Reviews of Interventions (http://www.cochrane-handbook.org/) [23]. The studies were assessed based on their risk of: (1) selection bias (biased allocation to interventions) due to inadequate generation of a randomised sequence, (2) attrition bias due to the amount, nature, or handling of incomplete outcome data, (3) reporting bias due to selective outcome reporting, and (4) risk of contamination of the intervention to the control group. For each type of possible bias, the articles 
were given a score -1 (high risk of bias), 0 (unclear risk of bias), or +1 (low risk of bias). Total score for bias ranged from -4 to +4 with studies scored between -4 and 0 considered as being of lower quality.

\subsection{Synthesis of Results}

Descriptive statistics (mean, SD, median, IQR, minimum, maximum) were used to summarize the structured data retrieved from the reviewed papers. Box-whisker plots were used to illustrate the data graphically.

When more than one type of intervention was tested, data from each arm of the study were considered as separate data points. A sensitivity analysis was performed to check for potential bias resulting from over-representation of studies with more than one intervention arm (see ESM).

In a first step, the mean adherence (point estimate) was considered for univariate and multivariate linear regression analysis. The dependent variable of those models was the difference in the adherence outcome between the intervention and control groups of each study. In the modelbuilding process, the effect of each available potentially confounding factor on the combined adherence outcome was tested using a linear meta-regression model.

The following were included as explanatory variables: medical condition, unit of allocation at randomization (randomization by patients or centers), average age, percentage of females, number of subjects in the intervention group, study duration (in weeks), the type of adherence outcome measure used in the analysis, the category of adherence-enhancing intervention, and the effect of the occupation of the person delivering the intervention (physician, nurse, pharmacists, or support partner). A stepwise regression procedure with forward selection and a $t$ statistic equal to 2 were used to define the final model.

For the studies in which the SD of the adherence outcome was reported together with its mean, we conducted a more formal estimation of the adherence-enhancing effect, measured by the difference between the adherence outcome of each intervention and the control group of each study (and aggregated $95 \%$ confidence interval) resulting from the different intervention types identified.

In the meta-analysis, a random effects model was used. The random effects model was fitted using a two-step approach [24]. First, the amount of residual/heterogeneity $\left(\tau^{2}\right)$ was estimated by random effects model using restricted maximum-likelihood method [24, 25]. Then the true effect was estimated using weighted least squares with weight of study $i$ equal to $w_{i}=1 /\left(v_{i}+\tau^{2}\right)$, where $v_{i}$ is the sampling variance of study $i$ and $\tau^{2}$ is the variability among the true effects that is not accounted for by the model. The analysis was executed using metafor package [26] implemented in $\mathrm{R}$ statistical package version 2.13.2. Total variability due to heterogeneity $\left(I^{2}\right)$ and $Q$ test were used to assess the statistical heterogeneity of the studies.

\subsection{Risk of Bias Across Studies}

A funnel plot was used to assess the presence of publication bias across studies. The funnel plot shows the individual observed effect sizes or outcomes on the $\mathrm{x}$ axis against the corresponding standard errors (i.e., the square root of the sampling variances) on the $y$ axis [27].

\section{Results}

\subsection{Study Selection}

Seventy-nine RCTs were included in the review. An overview of the review process and reasons for exclusion at the different steps are displayed in Fig. 1.

\subsection{Study Characteristics}

Individual study characteristics are listed in Appendix 2 in ESM. The majority of the studies were two-arm studies with one intervention group compared with one control group. However, 5 [28-32] of the 79 studies were 3-arm or 4-arm studies testing the efficacy of more than one adherence-enhancing component, each compared with the same control group. To check for potential bias resulting from over-representation of studies with more than one intervention arm, a sensitivity analysis was performed. In this analysis, studies with multiple intervention arms were (1) excluded, (2) only a single intervention arm was kept for analysis, or (3) each intervention arm was considered as a separate study. The resulting difference in parameter estimates between the three approaches was marginal $(<1 \%)$. Therefore, in the remainder of the paper, each intervention arm was considered as a separate study for analysis, yielding 87 cohorts totaling 5,237 subjects.

\subsubsection{Types of Participants}

Mean sample size expressed as number of subjects was 61.4 [range $(5 ; 1,113)$ ] in the usual care group and 64.1 [range $(4 ; 1,189)$ ] in the intervention group.

Average age expressed in years was 47.5 [range (3.0; $73.7)$ ] in the usual care group and 46.8 [range $(3.4 ; 76.2)$ ] in the intervention group. Five studies [33-37] designed adherence-enhancing interventions for children. Participants' demographic characteristics are presented in Tables 1 and 2 . 


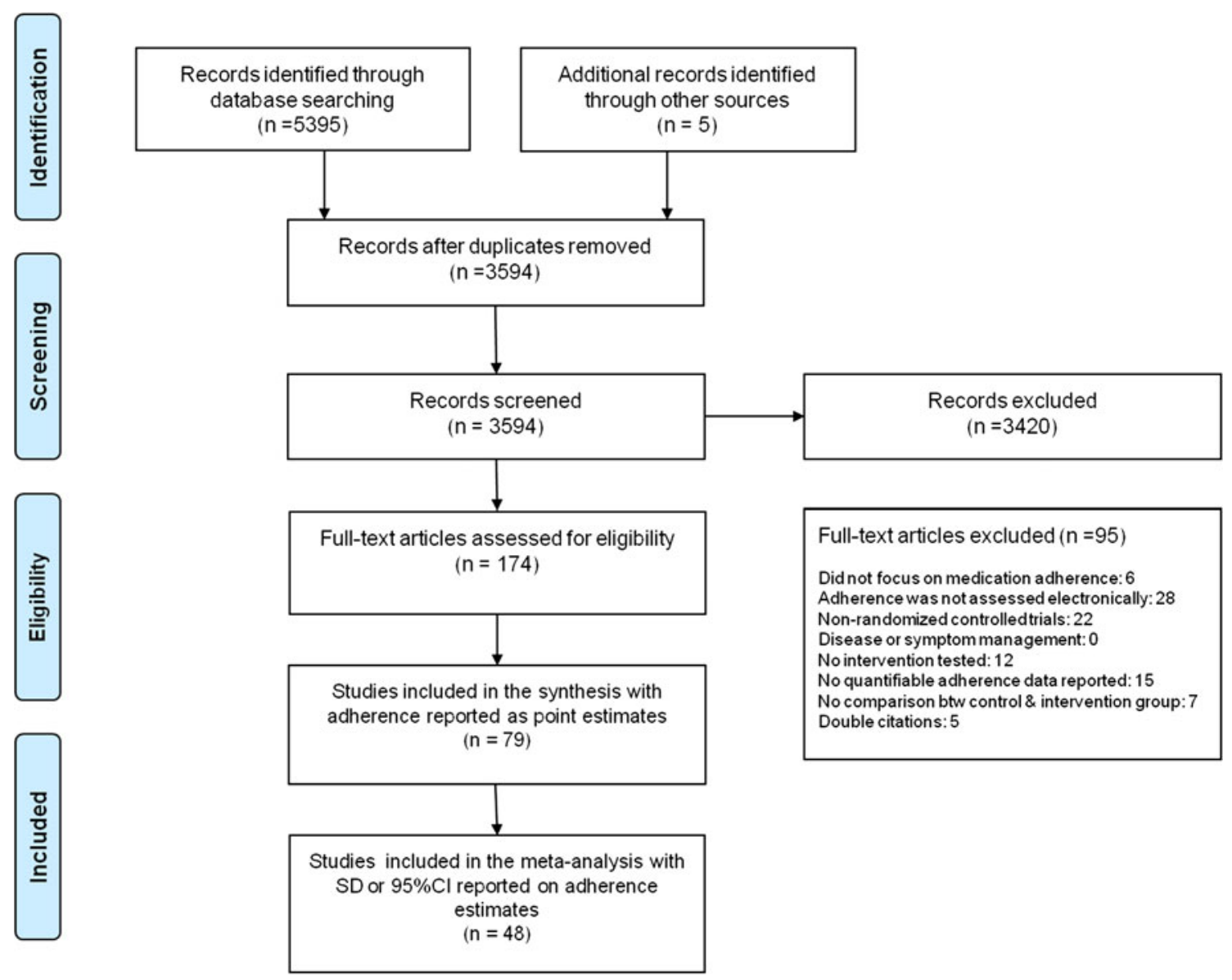

Fig. 1 Flow diagram of study selection process. $C I$ confidence interval, $S D$ standard deviation

Table 1 Group of patients targeted by the interventions in the 87 intervention groups

\begin{tabular}{lrr}
\hline Types of participants & $n$ & $\%$ \\
\hline Adult patients & 61 & 70.1 \\
Children & 5 & 5.7 \\
Women & 4 & 4.6 \\
Elderly & 3 & 3.4 \\
Socioeconomically disadvantaged patients & 3 & 3.4 \\
Postmenopausal women & 3 & 3.4 \\
Depressive patients & 2 & 2.3 \\
Soldiers & 1 & 1.1 \\
Adults commonly underrepresented in research & 1 & 1.1 \\
$\quad$ female, African American, Hispanics) & & \\
African Americans & 1 & 1.1 \\
Pregnant women & 1 & 1.1 \\
HIV patients with memory impairment & 1 & 1.1 \\
Methadone clinic patients & 1 & 1.1 \\
\hline
\end{tabular}

\subsubsection{Categorization of Interventions}

In 40 intervention groups, the efficacy of only one adherenceenhancing component was tested against a control group,
Table 2 Demographic characteristics of the 87 intervention groups by randomization group

\begin{tabular}{lll}
\hline & Usual care & $\begin{array}{l}\text { Intervention } \\
\text { group }\end{array}$ \\
\hline $\begin{array}{l}\text { Mean sample size expressed as } \\
\text { number of subjects (min-max }) \\
(n=82)\end{array}$ & $61.4(5-1,113)$ & $64.1(4-1,189)$ \\
$\begin{array}{l}\text { Average age expressed in years } \\
(\text { min-max })(n=60)\end{array}$ & $47.5(3.0-73.7)$ & $46.8(3.4-76.2)$ \\
$\begin{array}{l}\text { Gender expressed as \% female } \\
(n=59)\end{array}$ & $55.3 \%$ & $55.5 \%$ \\
$\begin{array}{l}\text { Ethnicity expressed as } \% \\
\text { Caucasian }(n=28)\end{array}$ & $36.0 \%$ & $39.5 \%$ \\
\hline
\end{tabular}

whereas in 47 intervention groups a combination of multiple adherence-enhancing components was tested (Fig. 2).

The average intervention period was 19.4 weeks with a range of 0-52 weeks. In two studies [38, 39], the intervention was delivered only on one occasion to the patients. In both of these studies, the patient post-intervention follow-up period ranged from 4 weeks [39] to 12 weeks [38]. The median duration of patient follow-up was 26 weeks [range $(4 ; 64)$ ]. 


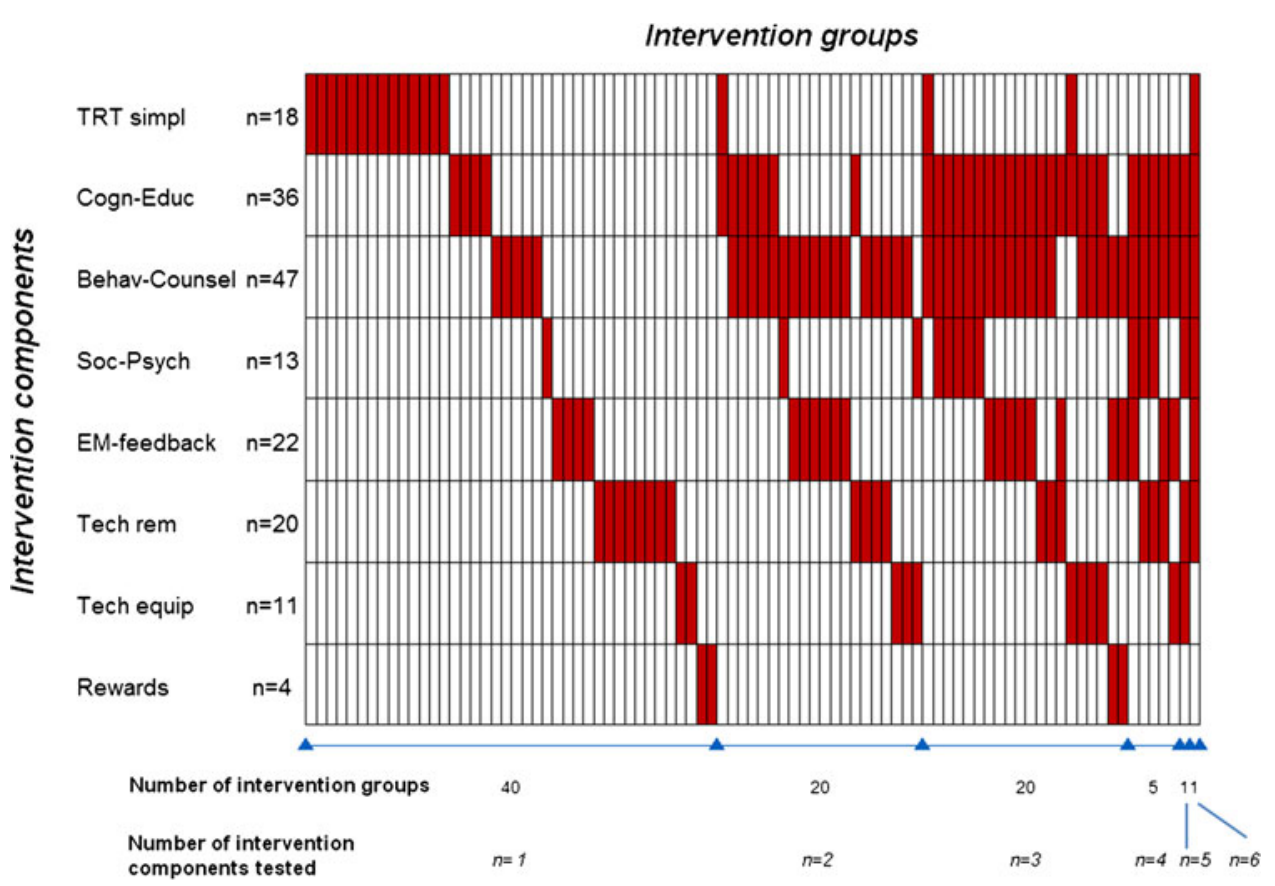

Fig. 2 Combination of adherence-enhancing components for each intervention group $(n=87)$. Each column stands for one intervention group. Intervention groups are ranked by number and types of components tested. In each intervention group, the tested intervention components are illustrated by red boxes. TRT simpl Interventions based on treatment simplification, $\operatorname{Cog} n-E d u c$ cognitive-educational

The frequency with which the intervention was delivered to patients was not included as a variable in the metaanalysis and was presumably optimized based on the type of intervention. In studies in which multiple intervention components were part of the adherence-enhancing intervention, each intervention component was reported with a different frequency. In several studies the frequencies were not clearly described [40-42].

Sixty-six of the 79 control groups received routine care, e.g., groups in which 'usual care' was provided to the patients and no adherence-enhancing intervention was tested. In some of these studies, the control groups were just named as 'standard of care' without a clear description of what was exactly provided to the patients of these groups.

In 13 control groups, however, an enhanced standard of care was provided to the patients. In one study [43], for example, the control group received the same care as the intervention group except for behavioral strategies. Control patients used self-monitoring of symptoms and attended the same number of visits as the intervention group.

\subsubsection{Types of Studies}

Within our selected RCTs, five were cluster randomized [44-48], and three were cross-over studies [49-51]. The publication years ranged from 1995 to 2011 with a peak in interventions, Behav-Counsel behavioral-counseling interventions, Soc-Psych social-psycho-affective intervention, EM-feedback interventions based on electronic-monitoring adherence feedback, Tech rem interventions based on a technical reminder use, Tech equip interventions based on a technical equipment use, Rewards any kind of rewards for adhering to medications

$2007(n=12)$. Out of five cluster-randomized studies, three $[44,45,47]$ took into account the within-cluster (within-center) correlation to analyze the adherence intervention effects.

The majority of the monitored medications were oral medication $(87.4 \%)$ monitored with the medication event monitoring system (MEMS) ${ }^{\circledR}$ caps $(85.1 \%)$. Table 3 illustrates the principal treatment characteristics of the 87 intervention groups.

The number of medications monitored ranged from 1 to 4 in each patient. In most of the studies $(89.0 \%)$, medication adherence was assessed electronically for one medication. In studies with multiple medications for a single indication, typically the medication with the most frequent or the most complicated dosing regimen was monitored. In the majority of these studies, however, adherence-enhancing interventions aimed to enhance medication adherence with all prescribed medications. In four studies [38, 40, 52, 53], it was not clear which and how many medications were monitored.

Disease categories were broad (23 different diseases); $38.0 \%$ of studies concerned HIV infection. Studies exclusively reported patients with chronic diseases (hypertension $13.9 \%$, asthma $12.7 \%$, heart failure $5.1 \%$, etc.).

Three studies [54-56] provided an estimate of the intervention's costs. The first study [54] reported an 
Table 3 Treatment characteristics of the 87 intervention groups

\begin{tabular}{|c|c|c|}
\hline & $n$ & $\%$ \\
\hline \multicolumn{3}{|l|}{ Medication intake } \\
\hline Oral & 76 & 87.4 \\
\hline Inhalation & 9 & 10.3 \\
\hline Eye drops & 1 & 1.1 \\
\hline Topical & 1 & 1.1 \\
\hline \multicolumn{3}{|l|}{ Dosing regimens } \\
\hline Once daily & 13 & 14.9 \\
\hline Twice daily & 13 & 14.9 \\
\hline Once daily vs. twice daily & 12 & 13.8 \\
\hline Once daily vs. thrice daily & 1 & 1.1 \\
\hline Once daily vs. once weekly & 1 & 1.1 \\
\hline $\begin{array}{l}\text { Variable (e.g., the medication with the most frequent } \\
\text { pill-taking schedule) }\end{array}$ & 31 & 35.6 \\
\hline Not reported & 16 & 18.4 \\
\hline \multicolumn{3}{|l|}{ Occupation of the person delivering the intervention } \\
\hline Nurse & 28 & 32.2 \\
\hline Physician & 14 & 16.1 \\
\hline $\begin{array}{l}\text { Others (research assistant, community health worker, } \\
\text { social worker, mobile phone, etc.) }\end{array}$ & 34 & 39.1 \\
\hline Pharmacist & 7 & 8.0 \\
\hline Support partner & 5 & 5.7 \\
\hline Psychologist & 2 & 2.3 \\
\hline Not reported & 11 & 12.6 \\
\hline \multicolumn{3}{|l|}{ Place where the intervention was provided } \\
\hline Hospital & 52 & 59.8 \\
\hline Home & 19 & 21.8 \\
\hline Hospital and home & 10 & 11.5 \\
\hline Pharmacy & 4 & 4.6 \\
\hline Primary care office & 1 & 1.1 \\
\hline Private practice and hospital & 1 & 1.1 \\
\hline \multicolumn{3}{|l|}{ Electronic medication-event monitoring } \\
\hline $\operatorname{MEMS}^{\circledR}$ & 74 & 85.1 \\
\hline Smartinhaler & 3 & 3.4 \\
\hline Metered dose inhaler (MDI) & 2 & 2.3 \\
\hline Doser CT & 3 & 3.4 \\
\hline RemindRX & 1 & 1.1 \\
\hline Dosing aid & 1 & 1.1 \\
\hline $\begin{array}{l}\text { Diskus adherence logger (DAL) and metered dose } \\
\text { inhaler (MDI) }\end{array}$ & 1 & 1.1 \\
\hline Med-Ic ${ }^{\mathrm{TM}}$ & 1 & 1.1 \\
\hline SIMPill & 1 & 1.1 \\
\hline
\end{tabular}

intervention based on daily text message reminders sent to the patients over a 4-week period (costs estimated per patient: US $\$ 3.60$, projected costs per year: US $\$ 46.80$; 2009). The second study [55] reported that the price for an alarmed vial used for 4 weeks ranged from US\$16 to US\$80 (2001). The third study reported a cost of US\$205 per patient [56] for a 1-year intervention delivered by a trained pharmacist providing patient-centered instructions and education (2007). No further conclusion on intervention costs could be derived given the limited information and the diversity of the studies.

\subsubsection{Types of Outcome Measures}

3.2.4.1 Adherence Definitions Twenty-five studies reported correct dosing, 49 studies reported adherence as taking adherence, 27 reported timing adherence, and 18 studies adherence as percentage of adherent patients.

Forty-eight studies reported mean adherence outcomes with a $95 \%$ CI or standard deviation and were therefore included in the random effects model of the meta-analysis.

3.2.4.2 Health Outcomes Among the 57 studies that reported data on clinical outcomes (72.2\%), only 8 [35, $44,52,57-61]$ reported a significant difference in clinical outcome between the intervention and the control groups.

Ducharme et al. [35] showed that children receiving a written action plan coupled with a prescription displayed significantly better asthma control with $40 \%$ more patients reporting less than two indicators of poor control (relative risk 1.36; $95 \%$ CI 1.04; 1.86). Asthma control was measured with the Asthma Quiz for Kids, which is a validated questionnaire measuring the number of indicators of poor asthma control.

Delmas et al. [44] concluded that adherence reinforcement strategies (feedback on bone turnover markers) were associated with a lower incidence of new radiologically determined vertebral fractures in osteoporosis patients (odds ratio 0.4; $95 \%$ CI 0.2-1.0).

Bogner et al. [52] reported fewer depressive symptoms (CES-D mean score difference between groups: 9.3; $p<0.01$ ), lower systolic blood pressure (systolic BP difference between groups: $14 \mathrm{mmHg} ; p<0.01$ ), and lower diastolic blood pressure (diastolic BP difference between groups: $9.2 \mathrm{mmHg} ; p<0.01$ ) in hypertensive patients of the intervention group (integrating depression treatment with hypertension management) compared to patients of the usual care group. Patients' treatment was monitored for 6 weeks.

Kardas et al. [57] noted that patients treated with oncedaily sulfonylurea drugs achieved significantly better glycaemic control than those treated with the twice-daily medication (HbA1c level difference between groups: $0.9 \% ; p<0.0001)$.

De Bruin et al. [58] showed that the number of HIV patients with an undetectable viral load increased in the intervention group (theory- and evidence-based underpinnings of the determinants and behavior change techniques) compared to the control group $(p<0.05)$.

Another study conducted by the group of Bogner and de-Vries [59] noted that participants in the integrated care 
intervention group (integrating depression treatment into care for type 2 diabetes mellitus) had lower levels of glycosylated hemoglobin $(p<0.05)$ and fewer depressive symptoms $(p<0.04)$ compared to participants in the usual care group at 12 weeks of diabetes treatment.

Rudd et al. [60] found that hypertensive patients randomized to the intervention group (home-based, physiciandirected, nurse-guided drug therapy) achieved greater reductions in office blood pressure values at 6 months than those receiving usual care (systolic BP difference between groups: $8.5 \mathrm{mmHg} ; \quad p<0.01$; diastolic $\mathrm{BP}$ difference between groups: $1.4 \mathrm{mmHg} ; p<0.05$ ).

Another study of Kardas [61] reported that the mean weekly number of chest pain episodes in angina pectoris patients was greater in patients with once-daily oral nitrates compared to patients randomized to the twice daily regimen $(0.94 \pm 4.32$ and $0.30 \pm 1.20$ episodes per week for the once and twice daily regimens, respectively; $p<0.0001)$.

\subsection{Synthesis of the Results}

Adherence data collected from the 87 intervention studies resulted in drug dosing history data compiled among 10,551 ambulatory patients. Patients randomized to an intervention group had an average combined adherence outcome of $74.3 \%$, which was $14.1 \%$ higher than in patients randomized to the control group $(60.2 \%)$. The median difference in the combined adherence outcome was $12.6 \%$ (range $-7.0,59.0 \%$; IQR $16 \%$ ).

The median difference in adherence measures between the control and intervention group at the end of the intervention period in studies that reported adherence as correct dosing $(n=25)$ was $14.0 \%$ (range $0.0,32.0 \%$; IQR $12.9 \%)$; in studies that reported taking adherence $(n=49)$, the median difference was $8.3 \%$ (range -7.0 , $49.0 \%$; IQR $12.7 \%$ ); in studies that reported timing adherence $(n=27)$, the median difference was $14.9 \%$ (range 2.0, 33.6\%; IQR 11.5\%); in studies that reported the percentage of adherent patients $(n=18)$, the median difference was $20.9 \%$ (range 1.8, $59.0 \%$; IQR $26.4 \%$ ).

\subsubsection{Potential Confounding Factors and Intervention Components that Affect Adherence Measures}

Univariate linear regression models were used to explore the association between each potential confounding factor and the difference in adherence measures between the control and intervention group. The models showed that study duration was the only factor that significantly affected adherence measures $(p<0.01)$. The longer the patient follow-up is, the smaller the difference in the adherence outcome between the study groups at the end of the study (Fig. 3). For each additional month of follow-up, the effect on adherence decreased by $1.0 \%$.

The number of subjects enrolled in the intervention group, subject gender, and average patients' age in the intervention group did not significantly affect this difference. For each increase in the number of intervention elements, the adherence outcome increased by $2.3 \%$ $(p=0.05)$. The results of the univariate linear regression model are summarized in Table 4. The unit allocation of randomization, by either patients (effect $14.1 \%$ ) or centers (effect $14.0 \%$ ), had no significant effect on the difference in the adherence outcome between the study groups at the end of the study (rank-sum test; $p=0.97$ ).

Figure 4 depicts the differences in the adherence outcome by intervention component tested in the intervention. Studies that included an EM-feedback type had a mean improvement of $19.9 \%$ (median $20.3 \%$ ), the highest average among all intervention components. On average, they were $7.7 \%$ more effective than studies testing intervention strategies that did not include such feedback (rank-sum test; $p=0.02$ ). Four studies used rewards as part of the intervention strategies, providing a mean improvement of adherence of $17.3 \%$ and a median of $22 \%$ (the highest median among all intervention components). On average, studies with rewards were $3.3 \%$ more effective than studies without rewards (ranksum test; $p=0.44$ ).

The occupation of the person who provided the intervention had no significant effect on adherence measures (rank-sum test; physician: effect $=1.0 \% p=0.99$; nurse: effect $=1.3 \% p=0.93 ;$ psychologist: effect $=4.7 \%$ $p=0.72$; pharmacist: effect $=5.4 \% p=0.58$; support partner: effect $=-5.8 \% p=0.45$ ).

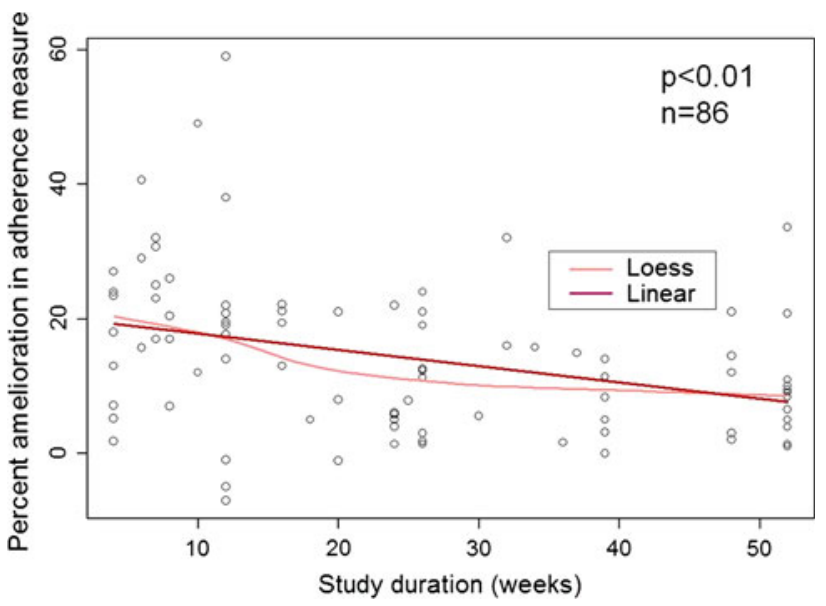

Fig. 3 Improvement in adherence outcome (percentage points) by study duration (linear regression model) $(n=86)$ *Loess: locally weighted scatterplot smoothing 
Table 4 Effect of potential confounding factors on adherence measures: results from univariate regression models

\begin{tabular}{llr}
\hline & $\begin{array}{l}\text { Effect on improvement of } \\
\text { adherence measure in \% }\end{array}$ & $P$ value \\
\hline $\begin{array}{l}\text { Study duration (in weeks) } \\
\text { Number of subjects in the } \\
\text { intervention group }\end{array}$ & -0.2430 & $<0.01$ \\
$\begin{array}{l}\text { Gender (percent of } \\
\text { females) }\end{array}$ & 0.0059 & 0.04 \\
$\begin{array}{l}\text { Patient's average age (in } \\
\text { years) }\end{array}$ & 0.0404 & 0.93 \\
$\begin{array}{l}\text { Number of intervention } \\
\text { elements }\end{array}$ & 2.2505 & 0.66 \\
\hline
\end{tabular}

\subsubsection{Significant Factors that Affect Adherence Outcomes: Results from the Multiple Regression Model}

When all variables were analyzed in a multiple regression model using a stepwise method, the variable indicator of EM-feedback type $(p<0.01)$ and cognitive-educational $(p=0.02)$ were the intervention components that remained significant in the final model. The model estimated an $8.8 \%$ increase in adherence when the intervention included an electronically monitored adherence feedback system and $5.0 \%$ increase in adherence when the intervention included a cognitive-educational component.

Study duration was also a significant factor that affected adherence measures $(p<0.01)$. For each additional month of follow-up, the effect on adherence decreased by $1.1 \%$. The variable percent adherent patient indicator (equal to 1 when the percentage of adherent patients is used as outcome variable, 0 otherwise) was significant in the model $(p<0.01)$, indicating that the percentage of adherent patients was not interchangeable with other adherence measures (correct dosing, taking adherence, timing adherence). The inclusion of the indicator variable in the model then served a correction when this percentage of adherent patients was used as an adherence measure.

\subsubsection{Effects of Adherence-Enhancing Interventions on Adherence Outcomes: Results from the Meta-Analysis}

Forty-eight of the 87 studies were included in the metaanalysis. The excluded studies did not report the variability

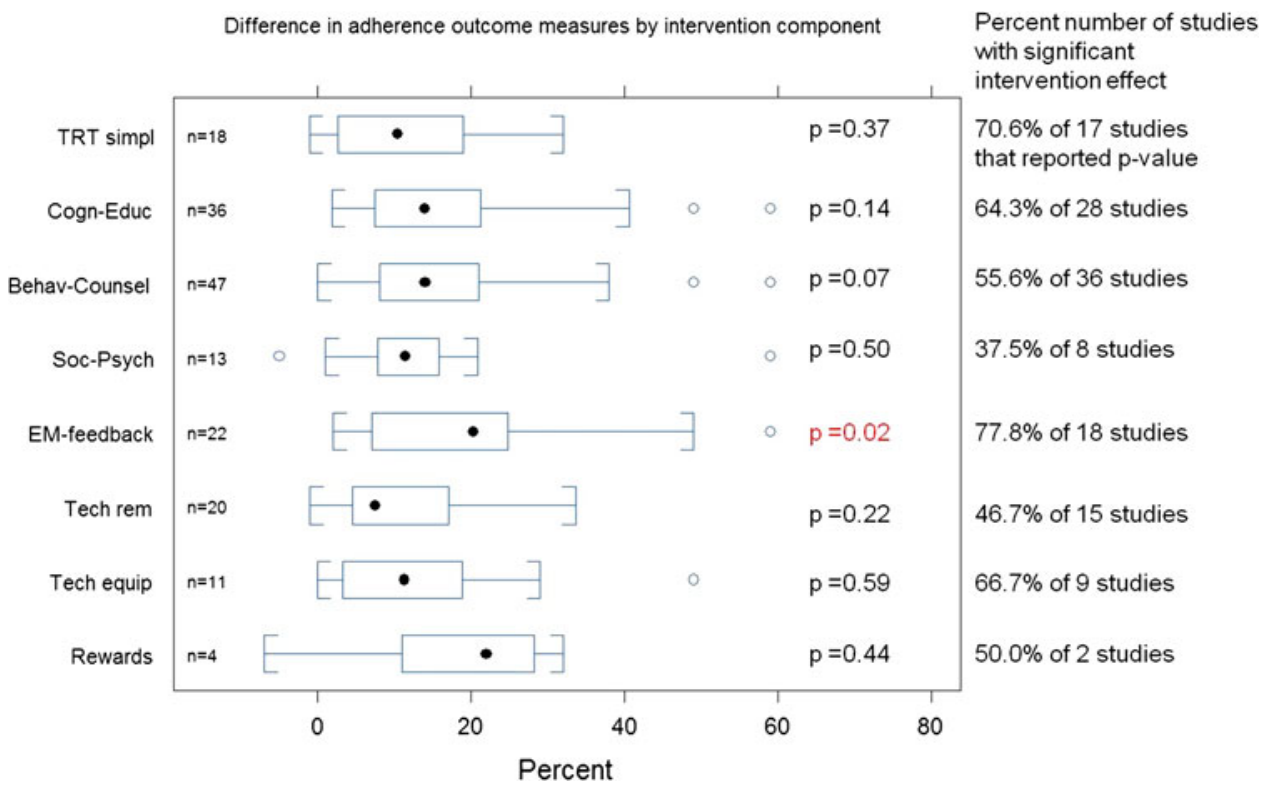

Fig. 4 Difference in the combined adherence outcome (expressed as percentages) between intervention and control group by adherenceenhancing component. The point near the middle of the box is the median. The lower and upper bounds of the box are the 25th and 75th percentile of the distribution. The ends of the whiskers represent the minimum and the maximum of the distribution after taking out the outliers. A point is considered as an outlier if it is above the 75th percentile of the distribution plus 1.5 of the interquartile range or if it is below the 25 th percentile of the distribution minus 1.5 of the interquartile range. The reported $p$ values are based on the Wilcoxon rank sum test to evaluate if there is any significant difference in adherence amelioration outcome between studies that included the

corresponding intervention component and studies that did not include this type of intervention component. TRT simpl Interventions based on treatment simplification, Cogn-Educ cognitive-educational interventions, Behav-Counsel behavioral-counseling interventions, Soc-Psych social-psycho-affective intervention, EM-feedback interventions based on electronic-monitoring adherence feedback, Tech rem interventions based on a technical reminder use, Tech equip interventions based on a technical equipment use, Rewards any kind of rewards for adhering to medications. The number of studies that reported a statistical comparison between the groups ( $p$ value) and the proportion of them that were statistically significant at the $5 \%$ level are depicted on the right-hand side 
of the effect of the intervention, which is needed to perform the meta-analysis.

The forest plot reported in Fig. 5 illustrates the percentage point differences in the adherence outcome between intervention and control groups from the individual studies as well as the estimated overall percentage point difference on adherence based on random effects model. The estimated overall percentage point difference between intervention and control groups of the 48 studies was $12.6 \%$ (95\% CI 9.4-15.8) with a wide variability in percentage point differences and confidence intervals between studies.

When explanatory variables were introduced in the mixed-effect model of the meta-analysis, the EM-feedback $(p<0.01)$ and cognitive-educational $(p=0.04)$ element of the intervention had a significant effect on patient adherence. The model estimated an $8.7 \%$ increase of the adherence measure when the intervention included an electronically monitored adherence feedback system and $5.6 \%$ increase of adherence measure when the intervention included an cognitive-educational component. Variable study duration was also significant in this model (1.2\% decrease for each month longer, $p<0.01$ ). The variable percent adherence indicator was borderline significant in this model $(p=0.09)$.

The combined adherence outcome in studies that tested the EM-feedback type as part of the intervention showed an overall percentage point difference of $19.8 \%(95 \% \mathrm{CI}$ 10.7-28.9). The overall percentage point difference was $10.3 \%$ (95\% CI 7.5-13.1) for the studies that did not test the EM-feedback type as part of the intervention. The improvement in adherence was $16.1 \% \quad(95 \%$ CI $10.7-21.6 \%$ ) in studies testing cognitive-educational components versus $10.1 \%$ (95\% CI $6.6-13.6 \%)$ in studies that did not include this type of intervention.

\subsection{Risk of Bias in Individual Studies}

Out of 87 studies, 12 studies (13.8\%) were considered of lower quality and prone to bias ( 1 had a score of -1 and 11 had a score of 0 ). Multiple regression analysis based on high quality studies only confirmed that EM-feedback $(p<0.01)$ and the cognitive-educational $(p=0.01)$ element of the intervention had a significant effect on patient adherence. The model estimated a $7.7 \%$ increase in the adherence measure when the intervention included an electronically monitored adherence feedback system and $5.9 \%$ increase in the adherence measure when the intervention included a cognitive-educational component. The variable study duration $(1.0 \%$ decrease for each month longer, $p<0.01)$ and the variable percent adherence indicator were significant in this model as well $(p<0.01)$.
Fig. 5 Percentage point differences in adherence outcomes (ordered by year of publication)

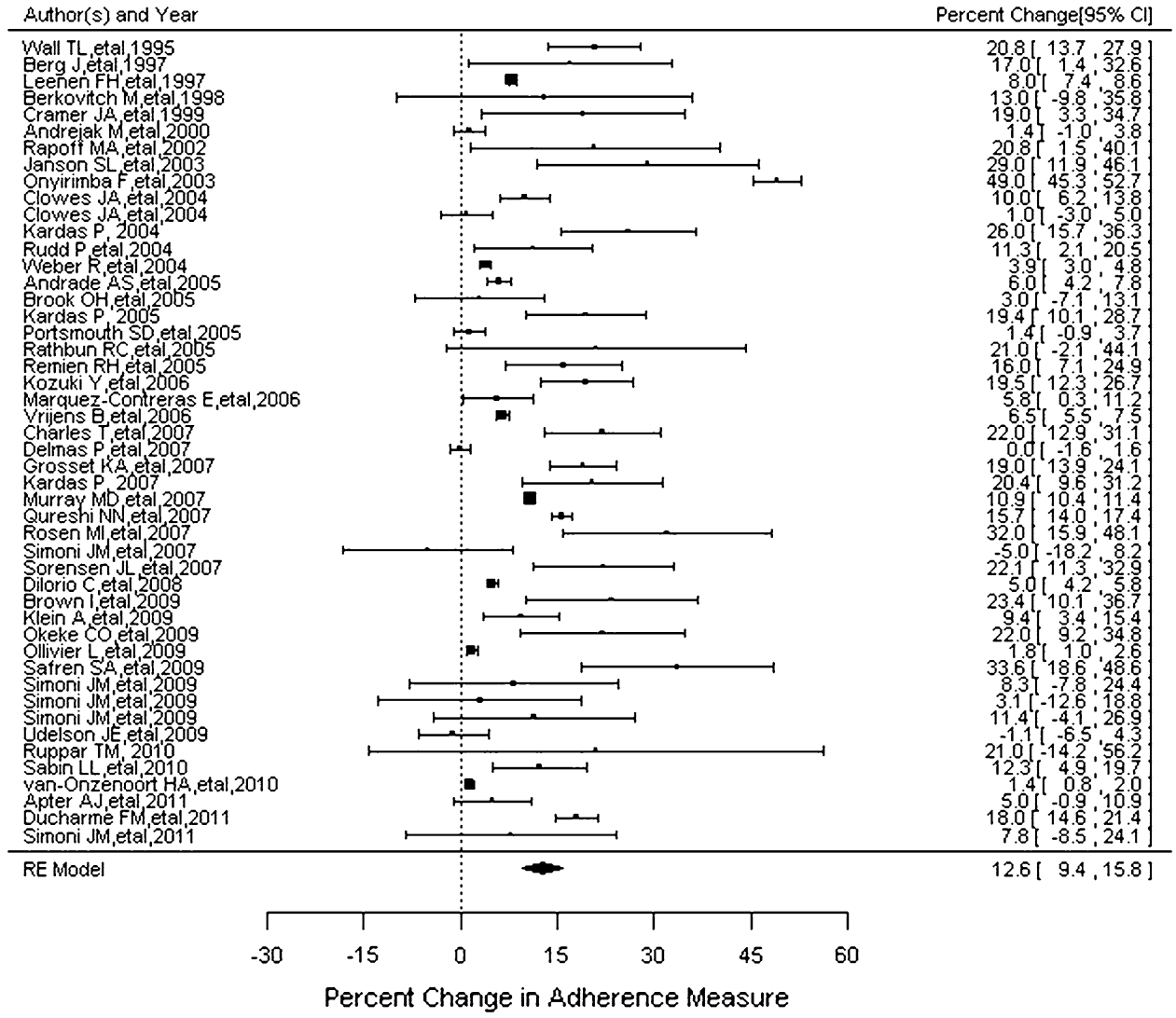




\subsection{Risk of Bias Across Studies}

The $Q$ statistic suggested considerable heterogeneity among the true effects $(p<0.01)$. The percentage of total variability due to heterogeneity $\left(I^{2}\right)$ based on this model was estimated as $99.9 \%$, showing that the studies were heterogeneous.

By using the standardized mean difference in the metaanalysis, the percentage of total variability due to heterogeneity $\left(I^{2}\right)$ based on this model was reduced slightly to $97.3 \%$. When explanatory variables were introduced in the mixed-effect model of the meta-analysis, the $Q$ statistic remained significant $(p<0.01)$, suggesting considerable heterogeneity among the true effects.

The funnel plot (Fig. 6) showed possible publication bias in studies with high variability of the intervention effect. The regression test for funnel plot asymmetry [62] showed that the observed mean difference in the adherence outcome between the intervention and control group was related to the standard error of the difference in the adherence outcome $(p<0.01)$. Studies with large intervention effects gave low $p$ values despite their high standard errors, and studies with $p<0.05$ were more likely to be published.

\section{Discussion}

\subsection{Summary of Evidence}

In this systematic literature review, we identified 79 RCTs reporting 87 pair-wise comparisons of interventions

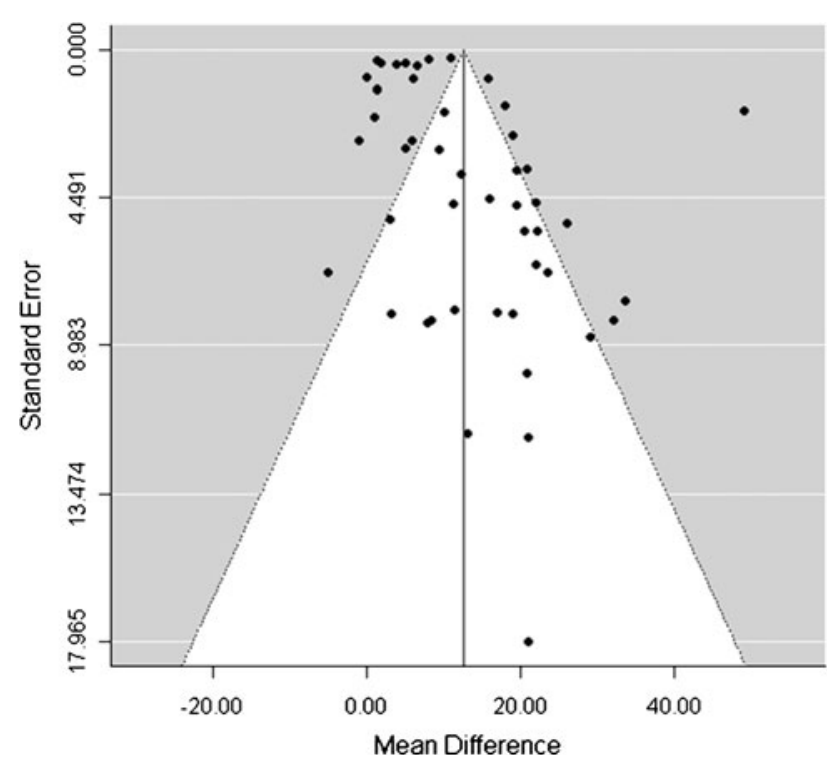

Fig. 6 Funnel plot to assess any publication bias across studies intended to enhance patient adherence to prescribed medications.

Patients randomized to an intervention group had, on average, an adherence outcome that was $14.1 \%$ higher than in patients randomized to standard care. This effect size is similar to the value reported in Peterson et al. [63] who conducted a meta-analysis on adherence-enhancing intervention trials and reported an overall effect size of 4-11\%, but no single strategy appeared to be best.

Relative to other intervention components, studies that included an EM-feedback type had the largest mean improvement in adherence measures. Studies using rewards as part of the intervention had the largest median improvement; however, probably due to its low sample size, the effect is not significant. Intervention strategies that included a focused discussion based on giving feedback to the patient of his/her recent dosing history data (EMfeedback) were $7.7 \%$ more effective than intervention strategies that did not include such feedback $(p=0.02)$.

The linear meta-regression analysis estimated an $8.8 \%$ increase in adherence when the intervention included feedback to the patients of their recent dosing history (EMfeedback) $(p<0.01)$. Our meta-analysis showed an average difference of $19.8 \%$ (95\% CI 10.7-28.9\%) in the combined adherence outcome between patients receiving EM-feedback versus control group-almost double the average difference among patients receiving an intervention that did not include the EM-feedback versus control group: $10.3 \%$ (95 \% CI 7.5-13.1\%).

This finding is consistent with the results of Kripalani and colleagues [21] who reported that the most common and effective forms of intervention were dosage simplification and repeated assessment of medication adherence with feedback. They used stringent inclusion criteria, considering only studies in chronic medical conditions that reported at least one measure of medication adherence and one clinical outcome, and with at least $80 \%$ follow-up of patients during 6 months of treatment. The methods used to measure adherence, however, varied widely in their studies.

Another study recently highlighted that EM-feedback can be a clinically useful tool when used in combination with other adherence-promoting treatment strategies aimed at enhancing medication adherence among chronically ill youths [64].

Though EM-feedback can be considered as a behavioral-counseling intervention, in terms of influencing patients' behavior by giving feedback on their recent drug dosing history, it was considered as a separate intervention component in our review. Given that our review focused on studies that assessed medication adherence through electronic medication-event monitoring, we sought to investigate how many studies utilized feedback on the patient's 
recent drug dosing history data in their intervention groups. Twenty-two intervention groups $(25.3 \%)$ actually included EM-feedback in their adherence-enhancing intervention.

Measurement-Guided Medication Management (MGMM) of adherence may be an approach to enhance adherence to medications in which reliable, detailed, recent, electronically compiled drug dosing history data are provided as feedback to the patient on his/her adherence to prescribed medications. It sets the stage for focused dialogue between the healthcare providers and their patients, reinforcing behavioral, social, and cognitive interventions.

Cognitive-educational interventions, designed to educate and motivate patients by instructional means, were also significant intervention strategies in our final model. The linear meta-regression analysis estimated a $5.0 \%$ increase in adherence when the intervention included a cognitive-educational component $(p=0.02)$.

Non-adherence to medication is recognized as a multifactorial and complex problem. Most studies included in our review assessed successfully complex interventions but did not assess the separate effects of the components, begging the question of whether all elements were required.

Kripalani's research group found in 2007 [21] that complex programs which utilized multiple interventions delivered over a longer period of time appeared more likely to achieve better outcomes. It is likely that these more complex interventions were effective because they address a greater number of the potential barriers impacting a patient's ability to adhere to therapy and provide reinforcement over time.

In a review, Haynes et al. [9] reported that several simple interventions appeared to improve adherence with short-term regimens, but interventions to improve medication use for chronic conditions appeared less effective overall and were often multifaceted, making it more difficult to synthesize published evaluation. This finding begs the question of whether multiple components are necessary or whether less complex interventions may be just as effective.

Since the frequency or dose of the different intervention components was not always clearly described in the studies or sometimes somewhat confusing because of the multiplicity of the components tested, we could not draw any conclusions on which intervention dose suits each component best.

Our review highlights, nevertheless, that several interventions were effective in improving adherence to medications. Few of them, however, were able to demonstrate an impact on clinical outcomes. While data on clinical outcomes were reported in 57 studies, only 8 studies $(14.0 \%)[35,44,52,57-61]$ reported a significant differ- ence in the effect of adherence-enhancing interventions on clinical outcomes. Of note is that most studies were not powered to show a difference in clinical outcomes, nor did they control for other potential influences on the clinical outcomes. There may also be a reporting bias; studies with significant adherence outcomes but not significant clinical outcomes may have not reported the non-significant clinical outcomes. Kripalani and colleagues [21] drew the same conclusion, having identified only a few studies demonstrating an impact on clinical outcomes, despite including only studies in which at least one measure of clinical outcome was reported.

The duration of the study follow-up showed a significant effect on the improvement in the combined adherence outcome, suggesting that the intervention effects on adherence tended to diminish over time. This evident diminution in improvement has an important clinical implication: it may not be realistic to expect a single episode of adherence-enhancing intervention to have longlasting effects. In two studies [38, 39], the intervention was delivered on one occasion, with a statistically significant effect on adherence outcomes, but the short follow-up period did not allow for an estimation of the intervention's waning effect over time. Interventions may have to be provided in a sustained fashion as an integral part of the treatment plan in order to achieve and maintain adherence.

The RCTs included in this review often lacked a detailed description of the control groups. Standard care provided to control participants in intervention trials may also contain effective behavior change techniques. De Bruin et al. [65] performed a meta-analysis on the impact of standard care on effects of adherence interventions in HIV patients. The control groups of their review-reportedly receiving "usual care"-were actually exposed to widely varying forms of effective adherence care. As the capacity of standard care increased, fewer behavioral problems remained, making it less likely that the intervention will be effective. These findings suggest that intervention effects will be systematically reduced in settings with higher levels of standard care.

Estimation of adherence to medication may differ according to the measure of adherence. Since we focused on studies that used electronically compiled drug-dosing histories, we could confidently exclude a potential bias present in other systematic reviews that would have been introduced by heterogeneous adherence measures. This method of electronically compiled drug dosing histories is considered to be the most reliable and the most detailed approach for estimating adherence to medication in ambulatory patients. Consequently, however, only a limited number of adherence-enhancing interventions may have been included in this review. 


\subsection{Limitations}

This meta-analysis was limited by the heterogeneity of the pooled data and the different medication adherence definitions.

Furthermore, we included each randomized controlled trial testing adherence-enhancing interventions. We did not apply any quality appraisal during the paper's selection process.

Given that the review was limited to EM monitoring of adherence, we have probably included more studies of MGMM than a review with broader inclusion criteria for adherence measurement. A publication bias might exist because only significant MGMM studies might be published, and inferior comparators might be used (investigators are sold to the concept of MGMM, and are "EM practitioners").

While studies on which electronic monitors are used to automatically compile dosing history data provide the most reliable estimate of adherence, some potential bias cannot be excluded. For example, non-adherent patients may refuse to participate in an adherence study, resulting in over-estimation of medication adherence. On the other hand, some patients who are adherent to the treatment may not use the electronic monitors appropriately (e.g., pocket dosing, weekly organizers, etc.), resulting in potential under-estimation of adherence. In general, those patients remain an exception and are typically screened out by the investigators, but it cannot be excluded that this phenomenon becomes less frequent among patients receiving EM-feedback.

Among the RCTs reviewed, considerable variability was evident with respect to study size, randomization method, frequency of intervention repetition, potential bias, operational definition of adherence, identification of the intervention types, study follow-up, definition of standard of care, and inclusion criteria used. The lack of detailed descriptions of control groups might have underestimated the intervention effects. In contrast to our review, McDonald et al. [10] conducted a descriptive review of the included studies instead of a quantitative summarization (i.e., meta-analysis) of findings across studies because of the heterogeneity in the methodology of adherenceenhancing intervention studies.

The majority of the papers did not clearly describe the methods used. This problem, also highlighted by several other authors [9, 66-68], led to discrepancies in data extraction between the two reviewers that needed to be resolved. A majority of studies reported significant differences in at least one adherence measure between the study groups (19.7\% significant differences vs. $8.5 \%$ non-significant differences), but a potential publication bias across the studies was identified through the funnel plot. We did not search conference abstracts or other sources to quantify this potential bias.
Finally, many of the studies $(38.0 \%)$ included in this review involved patients with HIV. The high effect size found in this review might be due to the assumption that differences in the perceived severity of the various health conditions in the studies may influence patients' response to adherence interventions.

\subsection{Future Research}

The limitations of this research support the need for future studies to adhere to guidelines concerning the design, conduct, analysis, and reporting of studies designed to assess the effects of adherence-enhancing interventions $[67,68]$.

Because there is a broad spectrum of reasons for nonadherence, including unintentional as well as intentional, any single intervention is not likely to be effective in enhancing medication adherence. The most effective approach might be based on patient stratification and personalized medicine, i.e., (1) identifying the patients with sub-optimal adherence; (2) identifying the origins for nonadherence, and (3) targeting those patients with a suitable intervention. It might be worthwhile to identify those patients most likely to respond to one form of intervention versus another and estimate the impact of adherenceenhancing interventions on clinical outcomes [9, 69].

Our review has shown that there is a large variability in intervention studies, and we have consequently identified several aspects that might help in improving the power of future intervention trials. More specifically, interventional trials should be adequately powered for a clinical endpoint, use a sound adherence measure, and be statistically robust.

Researchers should be informed that the efficacy of adherence-enhancing interventions wane over time, requiring repeated administration and adequate patient follow-up to ascertain not only long-term efficacy of interventions, but also the frequency of repeated interventions.

Finally, settings of clinical trials are different from real life, and researchers should place greater emphasis on testing adherence-enhancing interventions in real life settings, including evidence-based economic evaluations. Furthermore, most intervention studies are designed to change patient behavior, whereas healthcare system or multilevel interventions are still in an early research stage. It seems to be important to plan for suitable system-related intervention studies.

\section{Conclusions}

To our knowledge, this is the first review to focus on studies in which dosing histories were electronically compiled at rates of data sampling high-enough to provide 
adequate definition of when doses were or were not taken. Despite several limitations, this review supports the efficacy of EM-feedback and cognitive-educational interventions. Future research on adherence-enhancing interventions should address the multifaceted nature of non-adherence and utilize better study methods.

Acknowledgments We would like to thank Mr. Patrice Chalon (Belgian Health Care Knowledge Centre, Belgium) for sharing his experience with literature reviews and his help in defining the search strategies. The research leading to these results has received funding from the European Union's Seventh Framework Programme FP7/ 2007-2013 "Ascertaining Barriers for Compliance (ABC) Project" under grant agreement no. 223477.

Conflict of interest JD, PK, BV, JU are employees of AARDEX Group, a MWV Healthcare Company. SDG is a shareholder of Therasolve NV, Diepenbeek, Belgium. TR, DH, EF, PK, FD, and PL indicate that they have no financial relationships to this article to disclose.

Open Access This article is distributed under the terms of the Creative Commons Attribution Noncommercial License which permits any noncommercial use, distribution, and reproduction in any medium, provided the original author(s) and the source are credited. The exclusive right to any commercial use of the article is with Springer.

\section{References}

1. Osterberg L, Blaschke T. Adherence to medication. N Engl J Med. 2005;353(5):487-97.

2. Peterson AM, Takiya L, Finley R. Meta-analysis of interventions to improve drug adherence in patients with hyperlipidemia. Pharmacotherapy. 2003;23(1):80-7.

3. Corrao G, Parodi A, Nicotra F, Zambon A, Merlino L, Cesana $\mathrm{G}$, et al. Better compliance to antihypertensive medications reduces cardiovascular risk. J Hypertens. 2011;29(3):610-8.

4. Hughes D. When drugs don't work: economic assessment of enhancing compliance with interventions supported by electronic monitoring devices. Pharmacoeconomics. 2007;25(8):621-35.

5. Sokol MC, McGuigan KA, Verbrugge RR, Epstein RS. Impact of medication adherence on hospitalization risk and healthcare cost. Med Care. 2005;43(6):521-30.

6. Capgemini Consulting. Patient adherence: the next frontier in patient care. Vision and reality, 9th edn. Global research report by Capgemini Consulting, Study Director: Thomas Forissier, 2011.

7. Roebuck MC, Liberman JN, Gemmill-Toyama M, Brennan TA. Medication adherence leads to lower health care use and costs despite increased drug spending. Health Aff (Millwood). 2011;30(1):91-9.

8. Haynes RB, Yao X, Degani A, Kripalani S, Garg A, McDonald HP. Interventions to enhance medication adherence. Cochrane Database Syst Rev. 2005;(4):CD000011.

9. Haynes RB, Ackloo E, Sahota N, McDonald HP, Yao X. Interventions for enhancing medication adherence. Cochrane Database Syst Rev 2008;(2):CD000011.

10. McDonald HP, Garg AX, Haynes RB. Interventions to enhance patient adherence to medication prescriptions: scientific review. JAMA. 2002;288(22):2868-79.
11. Viswanathan M, Golin CE, Jones CD, Ashok M, Blalock SJ, Wines RC, et al. Interventions to improve adherence to selfadministered medications for chronic diseases in the United States: a systematic review. Ann Intern Med. 2012;157(11): 785-95.

12. Kass MA, Gordon M, Meltzer DW. Can ophthalmologists correctly identify patients defaulting from pilocarpine therapy? Am J Ophthalmol. 1986;101(5):524-30.

13. Norell SE. Accuracy of patient interviews and estimates by clinical staff in determining medication compliance. Soc Sci Med E. 1981;15(1):57-61.

14. Okeke CO, Quigley HA, Jampel HD, Ying GS, Plyler RJ, Jiang $\mathrm{Y}$, et al. Adherence with topical glaucoma medication monitored electronically the Travatan Dosing Aid Study. Ophthalmology. 2008;116(2):191-9.

15. Girard P, Sheiner LB, Kastrissios H, Blaschke TF. Do we need full compliance data for population pharmacokinetic analysis? J Pharmacokinet Biopharm. 1996;24(3):265-82.

16. Rubio A, Cox C, Weintraub M. Prediction of diltiazem plasma concentration curves from limited measurements using compliance data. Clin Pharmacokinet. 1992;22(3):238-46.

17. Vrijens B, Tousset E, Rode R, Bertz R, Mayer S, Urquhart J. Successful projection of the time course of drug concentration in plasma during a 1-year period from electronically compiled dosing-time data used as input to individually parameterized pharmacokinetic models. J Clin Pharmacol. 2005;45(4):461-7.

18. ABC (Ascertaining Barriers for Compliance) Project, funded by: European Commission, Seventh Framework Programme: Theme health-2007-3.1-5: better use of medicines. Grant agreement number: 223477. http://www.ABCproject.eu. None, 2011 (In press).

19. Liberati A, Altman DG, Tetzlaff J, Mulrow C, Gotzsche PC, Ioannidis JP, et al. The PRISMA statement for reporting systematic reviews and meta-analyses of studies that evaluate health care interventions: explanation and elaboration. Ann Intern Med. 2009;151(4):W65-94.

20. Berben L, Bogert L, Leventhal ME, Fridlund B, Jaarsma T, Norekval TM, et al. Which interventions are used by health care professionals to enhance medication adherence in cardiovascular patients? A survey of current clinical practice. Eur J Cardiovasc Nurs. 2011;10(1):14-21.

21. Kripalani S, Yao $X$, Haynes RB. Interventions to enhance medication adherence in chronic medical conditions: a systematic review. Arch Intern Med. 2007;167(6):540-50.

22. Osborn RL, Demoncada AC, Feuerstein M. Psychosocial interventions for depression, anxiety, and quality of life in cancer survivors: meta-analyses. Int $\mathrm{J}$ Psychiatry Med. 2006;36(1):13-34.

23. Higgins JPT, Green S, editors. Cochrane handbook for systematic reviews of interventions version 5.1.0 (updated March 2011). The Cochrane Collaboration, 2011. http://www.cochranehandbook.org.

24. Raudenbush SW. Analyzing effect sizes: random effects models. In: Cooper H, Hedges LV, Valentine JC, editors. The handbook of research synthesis and meta-analysis. 2nd ed. New York: Russell Sage Foundation; 2009, p. 295-315.

25 . Viechtbauer W. Bias and efficiency of meta-analytic variance estimators in the random-effects model. J Educ Behav Stat. 2005;30(3):261-93.

26. Viechtbauer W. Conducting meta-analyses in $\mathrm{R}$ with the metafor package. J Stat Softw. 2010;36(3):1-48.

27. Sterne JAC, Egger M. Funnel plots for detecting bias in metaanalysis: guidelines on choice of axis. J Clin Epidemiol. 2001;54:1046-55.

28. Clowes JA, Peel NF, Eastell R. The impact of monitoring on adherence and persistence with antiresorptive treatment for 
postmenopausal osteoporosis: a randomized controlled trial. J Clin Endocrinol Metab. 2004;89(3):1117-23.

29. Fulmer TT, Feldman PH, Kim TS, Carty B, Beers M, Molina M, et al. An intervention study to enhance medication compliance in community-dwelling elderly individuals. J Gerontol Nurs. 1999;25(8):6-14.

30. Rigsby MO, Rosen MI, Beauvais JE, Cramer JA, Rainey PM, O'Malley SS, et al. Cue-dose training with monetary reinforcement: pilot study of an antiretroviral adherence intervention. J Gen Intern Med. 2000;15(12):841-7.

31. Simoni JM, Huh D, Frick PA, Pearson CR, Andrasik MP, Dunbar PJ, et al. Peer support and pager messaging to promote antiretroviral modifying therapy in Seattle: a randomized controlled trial. J Acquir Immune Defic Syndr. 2009;52(4):465-73.

32. Pop-Eleches C, Thirumurthy H, Habyarimana JP, Zivin JG, Goldstein MP, de Walque D, et al. Mobile phone technologies improve adherence to antiretroviral treatment in a resourcelimited setting: a randomized controlled trial of text message reminders. AIDS. 2011;25:825-34.

33. Berkovitch M, Papadouris D, Shaw D, Onuaha N, Dias C, Olivieri NF. Trying to improve compliance with prophylactic penicillin therapy in children with sickle cell disease. Br J Clin Pharmacol. 1998;45(6):605-7.

34. Burgess SW, Sly PD, Devadason SG. Providing feedback on adherence increases use of preventive medication by asthmatic children. J Asthma Off J Assoc Care Asthma. 2010;47:198-201.

35. Ducharme FM, Zemek RL, Chalut D, McGillivray D, Noya FJ, Resendes S, et al. Written action plan in pediatric emergency room improves asthma prescribing, adherence, and control. Am J Respir Crit Care Med. 2011;183(2):195-203.

36. Rapoff MA, Belmont J, Lindsley C, Olson N, Morris J, Padur J. Prevention of nonadherence to nonsteroidal anti-inflammatory medications for newly diagnosed patients with juvenile rheumatoid arthritis. Health Psychol. 2002;21(6):620-3.

37. Burgess SW, Sly PD, Cooper DM, Devadason SG. Novel spacer device does not improve adherence in childhood asthma. Pediatr Pulmonol. 2007;42(8):736-9.

38. Grosset KA, Grosset DG. Effect of educational intervention on medication timing in Parkinson's disease: a randomized controlled trial. BMC Neurol. 2007;7:20.

39. Brown I, Sheeran P, Reuber M. Enhancing antiepileptic drug adherence: a randomized controlled trial. Epilepsy Behav. 2009;16(4):634-9.

40. Klein A, Otto G, Kramer I. Impact of a pharmaceutical care program on liver transplant patients' compliance with immunosuppressive medication: a prospective, randomized, controlled trial using electronic monitoring. Transplantation. 2009;87(6):839-47.

41. Rathbun RC, Farmer KC, Stephens JR, Lockhart SM. Impact of an adherence clinic on behavioral outcomes and virologic response in treatment of HIV infection: a prospective, randomized, controlled pilot study. Clin Ther. 2005;27(2):199-209.

42. Rosen MI, Dieckhaus K, McMahon TJ, Valdes B, Petry NM, Cramer J, et al. Improved adherence with contingency management. AIDS Patient Care STDS. 2007;21(1):30-40.

43. Janson SL, McGrath KW, Covington JK, Cheng SC, Boushey HA. Individualized asthma self-management improves medication adherence and markers of asthma control. J Allergy Clin Immunol. 2009;123(4):840-6.

44. Delmas PD, Vrijens B, Eastell R, Roux C, Pols HA, Ringe JD, et al. Effect of monitoring bone turnover markers on persistence with risedronate treatment of postmenopausal osteoporosis. J Clin Endocrinol Metab. 2007;92(4):1296-304.

45. Dusing R, Handrock R, Klebs S, Tousset E, Vrijens B. Impact of supportive measures on drug adherence in patients with essential hypertension treated with valsartan: the randomized, open-label, parallel group study VALIDATE. J Hypertens. 2009;27(4): 894-901.

46. Hyder SM, Persson LA, Chowdhury AM, Ekstrom EC. Do sideeffects reduce compliance to iron supplementation? A study of daily- and weekly-dose regimens in pregnancy. J Health Popul Nutr. 2002;20(2):175-9.

47. Qureshi NN, Hatcher J, Chaturvedi N, Jafar TH. Effect of general practitioner education on adherence to antihypertensive drugs: cluster randomised controlled trial. BMJ. 2007;335(7628):1030.

48. Vrijens B, Belmans A, Matthys K, de Klerk E, Lesaffre E. Effect of intervention through a pharmaceutical care program on patient adherence with prescribed once-daily atorvastatin. Pharmacoepidemiol Drug Saf. 2006;15(2):115-21.

49. Safren SA, Hendriksen ES, Desousa N, Boswell SL, Mayer KH. Use of an on-line pager system to increase adherence to antiretroviral medications. AIDS Care. 2003;15(6):787-93.

50. Wilson IB, Laws MB, Safren SA, Lee Y, Lu M, Coady W, et al. Provider-focused intervention increases adherence-related dialogue but does not improve antiretroviral therapy adherence in persons with HIV. J Acquir Immune Defic Syndr. 2010;3:338-47.

51. Adler LA, Lynch LR, Shaw DM, Wallace SP, Ciranni MA, Briggie AM, et al. Medication adherence and symptom reduction in adults treated with mixed amphetamine salts in a randomized crossover study. Postgrad Med. 2011;123(5):71-9.

52. Bogner HR, de Vries HF. Integration of depression and hypertension treatment: a pilot, randomized controlled trial. Ann Fam Med. 2008;6(4):295-301.

53. Weber R, Christen L, Christen S, Tschopp S, Znoj H, Schneider $\mathrm{C}$, et al. Effect of individual cognitive behaviour intervention on adherence to antiretroviral therapy: prospective randomized trial. Antivir Ther. 2004;9(1):85-95.

54. Ollivier L, Romand O, Marimoutou C, Michel R, Pognant C, Todesco A, et al. Use of short message service (SMS) to improve malaria chemoprophylaxis compliance after returning from a malaria endemic area. Malar J. 2009;8:236.

55. Frick PA, Lavreys L, Mandaliya K, Kreiss JK. Impact of an alarm device on medication compliance in women in Mombasa, Kenya. Int J STD AIDS. 2001;12(5):329-33.

56. Murray MD, Young J, Hoke S, Tu W, Weiner M, Morrow D, et al. Pharmacist intervention to improve medication adherence in heart failure: a randomized trial. Ann Intern Med. 2007;146(10):714-25.

57. Kardas P. The DIACOM study (effect of DosIng frequency of oral antidiabetic agents on the COMpliance and biochemical control of type 2 diabetes). Diabetes Obes Metab. 2005;7(6): $722-8$.

58. de Bruin M, Hospers HJ, van Breukelen GJP, Kok G, Koevoets WM, Prins JM. Electronic monitoring-based counseling to enhance adherence among HIV-infected patients: a randomized controlled trial. Health Psychol. 2010;29(4):421-8.

59. Bogner HR, de-Vries HF. Integrating type 2 diabetes mellitus and depression treatment among African Americans: a randomized controlled pilot trial. Diabetes Educ. 2010;36:284-92.

60. Rudd P, Miller NH, Kaufman J, Kraemer HC, Bandura A, Greenwald G, et al. Nurse management for hypertension. A systems approach. Am J Hypertens. 2004;17(10):921-7.

61. Kardas P. Comparison of once daily versus twice daily oral nitrates in stable angina pectoris. Am J Cardiol. 2004;94(2):213-6.

62. Egger M, Davey Smith G, Schneider M, Minder C. Bias in meta-analysis detected by a simple, graphical test. Brit Med J. 1997;315:629-34.

63. Peterson AM, Takiya L, Finley R. Meta-analysis of trials of interventions to improve medication adherence. Am J Health Syst Pharm. 2003;60(7):657-65.

64. Herzer M, Ramey C, Rohan J, Cortina S. Incorporating electronic monitoring feedback into clinical care: a novel and 
promising adherence promotion approach. Clin Child Psychol Psychiatry. 2012;17(4):505-18.

65. de Bruin M, Viechtbauer W, Schaalma HP, Abraham C, Hospers HJ. Standard care impact on effects of highly active antiretroviral therapy adherence interventions. Arch Intern Med. 2010;170(3):240-50.

66. Christensen A, Osterberg LG, Hansen EH. Electronic monitoring of patient adherence to oral antihypertensive medical treatment: a systematic review. J Hypertens. 2009;27(8):1540-51.

67. Gwadry-Sridhar FH, Manias E, Zhang Y, Roy A, Yu-Isenberg $\mathrm{K}$, Hughes DA, et al. A framework for planning and critiquing medication compliance and persistence research using prospective study designs. Clin Ther. 2009;31(2):421-35.

68. Peterson AM, Nau DP, Cramer JA, Benner J, Gwadry-Sridhar F, Nichol M. A checklist for medication compliance and persistence studies using retrospective databases. Value Health. 2007;10(1):3-12.

69. Conn VS, Hafdahl AR, Cooper PS, Ruppar TM, Mehr DR, Russell CL. Interventions to improve medication adherence among older adults: meta-analysis of adherence outcomes among randomized controlled trials. Gerontologist. 2009;49(4):447-62.

70. Wall TL, Sorensen JL, Batki SL, Delucchi KL, London JA, Chesney MA. Adherence to zidovudine (AZT) among HIVinfected methadone patients: a pilot study of supervised therapy and dispensing compared to usual care. Drug Alcohol Depend. 1995;37(3):261-9.

71. Berg J, Dunbar-Jacob J, Sereika SM. An evaluation of a selfmanagement program for adults with asthma. Clin Nurs Res. 1997;6(3):225-38.

72. Leenen FH, Wilson TW, Bolli P, Larochelle P, Myers M, Handa $\mathrm{SP}$, et al. Patterns of compliance with once versus twice daily antihypertensive drug therapy in primary care: a randomized clinical trial using electronic monitoring. Can J Cardiol. 1997;13(10):914-20.

73. Mounier-Vehier C, Bernaud C, Carre A, Lequeuche B, Hotton JM, Charpentier JC. Compliance and antihypertensive efficacy of amlodipine compared with nifedipine slow-release. Am J Hypertens. 1998;11(4 Pt 1):478-86.

74. Cramer JA, Rosenheck R. Enhancing medication compliance for people with serious mental illness. J Nerv Ment Dis. 1999;187(1):53-5.

75. Andrejak M, Genes N, Vaur L, Poncelet P, Clerson P, Carre A. Electronic pill-boxes in the evaluation of antihypertensive treatment compliance: comparison of once daily versus twice daily regimen. Am J Hypertens. 2000;13(2):184-90.

76. Bouvy ML, Heerdink ER, Urquhart J, Grobbee DE, Hoes AW, Leufkens HG. Effect of a pharmacist-led intervention on diuretic compliance in heart failure patients: a randomized controlled study. J Card Fail. 2003;9(5):404-11.

77. Janson SL, Fahy JV, Covington JK, Paul SM, Gold WM, Boushey HA. Effects of individual self-management education on clinical, biological, and adherence outcomes in asthma. Am J Med. 2003;115(8):620-6.

78. Onyirimba F, Apter A, Reisine S, Litt M, McCusker C, Connors $M$, et al. Direct clinician-to-patient feedback discussion of inhaled steroid use: its effect on adherence. Ann Allergy Asthma Immunol. 2003;90(4):411-5.

79. Rawlings MK, Thompson MA, Farthing CF, Brown LS, Racine $\mathrm{J}$, Scott RC, et al. Impact of an educational program on efficacy and adherence with a twice-daily lamivudine/zidovudine/abacavir regimen in underrepresented $\mathrm{HIV}$-infected patients. J Acquir Immune Defic Syndr. 2003;34(2):174-83.

80. Smith SR, Rublein JC, Marcus C, Brock TP, Chesney MA. A medication self-management program to improve adherence to HIV therapy regimens. Patient Educ Couns. 2003;50(2):187-99.
81. Andrade AS, McGruder HF, Wu AW, Celano SA, Skolasky RL Jr, Selnes OA, et al. A programmable prompting device improves adherence to highly active antiretroviral therapy in HIV-infected subjects with memory impairment. Clin Infect Dis. 2005;41(6):875-82.

82. Brook OH, van Hout H, Stalman W, Nieuwenhuyse H, Bakker B, Heerdink E, et al. A pharmacy-based coaching program to improve adherence to antidepressant treatment among primary care patients. Psychiatr Serv. 2005;56(4):487-9.

83. Portsmouth SD, Osorio J, McCormick K, Gazzard BG, Moyle GJ. Better maintained adherence on switching from twice-daily to once-daily therapy for HIV: a 24-week randomized trial of treatment simplification using stavudine prolonged-release capsules. HIV Med. 2005;6(3):185-90.

84. Remien RH, Stirratt MJ, Dolezal C, Dognin JS, Wagner GJ, Carballo-Dieguez A, et al. Couple-focused support to improve HIV medication adherence: a randomized controlled trial. AIDS. 2005;19(8):807-14.

85. Schmitz JM, Sayre SL, Stotts AL, Rothfleisch J, Mooney ME. Medication compliance during a smoking cessation clinical trial: a brief intervention using MEMS feedback. J Behav Med. 2005;28(2):139-47.

86. DeGeest S, Schafer-Keller P, Denhaerynck K, Thannberger N, Kofer S, Bock A, et al. Supporting medication adherence in renal transplantation (SMART): a pilot RCT to improve adherence to immunosuppressive regimens. Clin Transplant. 2006;20(3):359-68.

87. Holzemer WL, Bakken S, Portillo CJ, Grimes R, Welch J, Wantland D, et al. Testing a nurse-tailored HIV medication adherence intervention. Nurs Res. 2006;55(3):189-97.

88. Kozuki Y, Schepp KG. Visual-feedback therapy for antipsychotic medication adherence. Int Clin Psychopharmacol. 2006;21(1):57-61.

89. Marquez-Contreras E, Martell-Claros N, Gil-Guillen V, de la Figuera-Von Wichmann M, Casado-Martinez JJ, Martin-de Pablos JL, et al. Efficacy of a home blood pressure monitoring programme on therapeutic compliance in hypertension: the EAPACUM-HTA study. J Hypertens. 2006;24(1):169-75.

90. Wagner GJ, Kanouse DE, Golinelli D, Miller LG, Daar ES, Witt $\mathrm{MD}$, et al. Cognitive-behavioral intervention to enhance adherence to antiretroviral therapy: a randomized controlled trial (CCTG 578). AIDS. 2006;20(9):1295-302.

91. Williams AB, Fennie KP, Bova CA, Burgess JD, Danvers KA, Dieckhaus KD. Home visits to improve adherence to highly active antiretroviral therapy: a randomized controlled trial. J Acquir Immune Defic Syndr. 2006;42(3):314-21.

92. Charles T, Quinn D, Weatherall M, Aldington S, Beasley R, Holt S. An audiovisual reminder function improves adherence with inhaled corticosteroid therapy in asthma. J Allergy Clin Immunol. 2007;4:811-6.

93. Kardas P. Compliance, clinical outcome, and quality of life of patients with stable angina pectoris receiving once-daily betaxolol versus twice daily metoprolol: a randomized controlled trial. Vasc Health Risk Manag. 2007;3(2):235-42.

94. Mooney ME, Sayre SL, Hokanson PS, Stotts AL, Schmitz JM. Adding MEMS feedback to behavioral smoking cessation therapy increases compliance with bupropion: a replication and extension study. Addict Behav. 2007;32(4):875-80.

95. Parienti JJ, Massari V, Reliquet V, Chaillot F, Le MG, Arvieux $\mathrm{C}$, et al. Effect of twice-daily nevirapine on adherence in HIV-1infected patients: a randomized controlled study. AIDS. 2007;21(16):2217-22.

96. Simoni JM, Pantalone DW, Plummer MD, Huang B. A randomized controlled trial of a peer support intervention targeting antiretroviral medication adherence and depressive symptomatology 
in HIV-positive men and women. Health Psychol. 2007;26(4):488-95.

97. Sorensen JL, Haug NA, Delucchi KL, Gruber V, Kletter E, Batki SL, et al. Voucher reinforcement improves medication adherence in HIV-positive methadone patients: a randomized trial. Drug Alcohol Depend. 2007;88(1):54-63.

98. Boyle BA, Jayaweera D, Witt MD, Grimm K, Maa JF, Seekins DW. Randomization to once-daily stavudine extended release/ lamivudine/efavirenz versus a more frequent regimen improves adherence while maintaining viral suppression. HIV Clin Trials. 2008;9(3):164-76.

99. Dilorio C, McCarty F, Resnicow K, McDonnell HM, Soet J, Yeager $\mathrm{K}$, et al. Using motivational interviewing to promote adherence to antiretroviral medications: a randomized controlled study. AIDS Care. 2008;20(3):273-83.

100. Koenig LJ, Pals SL, Bush T, Pratt PM, Stratford D, Ellerbrock TV. Randomized controlled trial of an intervention to prevent adherence failure among HIV-infected patients initiating antiretroviral therapy. Health Psychol. 2008;27(2):159-69.

101. Maitland D, Jackson A, Osorio J, Mandalia S, Gazzard BG, Moyle GJ. Switching from twice-daily abacavir and lamivudine to the once-daily fixed-dose combination tablet of abacavir and lamivudine improves patient adherence and satisfaction with therapy. HIV Med. 2008;9(8):667-72.

102. Ogedegbe G, Chaplin W, Schoenthaler A, Statman D, Berger D, Richardson $\mathrm{T}$, et al. A practice-based trial of motivational interviewing and adherence in hypertensive African Americans. Am J Hypertens. 2008;21(10):1137-43.

103. Okeke CO, Quigley HA, Jampel HD, Ying GS, Plyler RJ, Jiang $\mathrm{Y}$, et al. Interventions improve poor adherence with once daily glaucoma medications in electronically monitored patients. Ophthalmology. 2009;116(12):2286-93.

104. Safren SA, O'Cleirigh C, Tan JY, Raminani SR, Reilly LC, Otto $\mathrm{MW}$, et al. A randomized controlled trial of cognitive behavioral therapy for adherence and depression (CBT-AD) in HIV-infected individuals. Health Psychol. 2009;28(1):1-10.

105. Udelson JE, Pressler SJ, Sackner-Bernstein J, Massaro J, Ordronneau P, Lukas MA, et al. Adherence with once daily versus twice daily carvedilol in patients with heart failure: the Compliance And Quality of Life Study Comparing Once-Daily
Controlled-Release Carvedilol CR and Twice-Daily ImmediateRelease Carvedilol IR in Patients with Heart Failure (CASPER) Trial. J Card Fail. 2009;15(5):385-93.

106. Hou MY, Hurwitz S, Kavanagh E, Fortin J, Goldberg AB. Using daily text-message reminders to improve adherence with oral contraceptives: a randomized controlled trial. Obstet Gynecol. 2010;116(3):633-40.

107. Ruppar TM. Randomized pilot study of a behavioral feedback intervention to improve medication adherence in older adults with hypertension. J Cardiovasc Nurs. 2010;25(6):470-9.

108. Sabin LL, DeSilva MB, Hamer DH, Xu K, Zhang J, Li T, et al. Using electronic drug monitor feedback to improve adherence to antiretroviral therapy among HIV-positive patients in China. AIDS Behav. 2010;14(3):580-9.

109. van-Onzenoort HA, Verberk WJ, Kroon AA, Kessels AG, Nelemans PJ, van-der-Kuy PH, et al. Effect of self-measurement of blood pressure on adherence to treatment in patients with mild-to-moderate hypertension. J Hypertens. 2010;28:622-7.

110. Yentzer BA, Ade RA, Fountain JM, Clark AR, Taylor SL, Fleischer AB Jr, et al. Simplifying regimens promotes greater adherence and outcomes with topical acne medications: a randomized controlled trial. Cutis. 2010;86(2):103-8.

111. Apter AJ, Wang X, Bogen DK, Rand CS, McElligott S, Polsky $\mathrm{D}$, et al. Problem solving to improve adherence and asthma outcomes in urban adults with moderate or severe asthma: a randomized controlled trial. J Allergy Clin Immunol. 2011;128: 516-23.

112. Clerisme-Beaty EM, Bartlett SJ, Teague WG, Lima J, Irvin CG, Cohen R, et al. The Madison Avenue effect: how drug presentation style influences adherence and outcome in patients with asthma. J Allergy Clin Immunol. 2011;127:406-11.

113. Holstad MM, DiIorio C, Kelley ME, Resnicow K, Sharma S. Group motivational interviewing to promote adherence to antiretroviral medications and risk reduction behaviors in HIV infected women. AIDS Behav. 2011;15(5):885-96.

114. Simoni JM, Chen WT, Huh D, Fredriksen-Goldsen KI, Pearson $\mathrm{C}$, Zhao $\mathrm{H}$, et al. A preliminary randomized controlled trial of a nurse-delivered medication adherence intervention among HIVpositive outpatients initiating antiretroviral therapy in Beijing, China. AIDS Behav. 2011;15(5):919-29. 